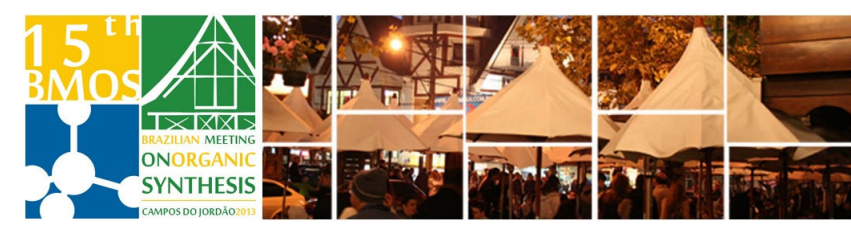

\title{
Synthesis of the C1-C13 fragment of Nhatrangin A
}

\section{Ellen Christine Polo and Luiz Carlos Dias}

\author{
Instituto de Química-UNICAMP, P. O. Box 6154, 13084-971, Campinas, SP-Brazil \\ *Idias@iqm.unicamp.br
}

Keywords: Total synthesis, Nhatrangin A, Aldol Reaction

\section{INTRODUCTION}

Nhatrangin $A$ (1) is a polyketide metabolite containing 6 stereogenic centers, isolated in 2010 from a Vietnamese collection of marine cyanobacterium Lyngbya majuscula. Its structure was assigned based on spectrometric and spectroscopic methods including 2D NMR experiments. ${ }^{1}$

Figure 1. Nhatrangin $A$

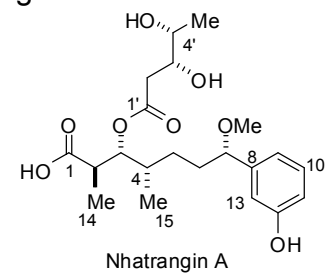

This work aimed to the synthesis of the $\mathrm{C} 1-\mathrm{C} 13$ fragment of nhatrangin $A$.

\section{RESULTS AND DISCUSSION}

Our studies began with the preparation of aldehyde 3 (Scheme 1). Treatment of (S)-Roche ester 2 with PMB 2,2,2-trichloroacetimidate (PMBTCA) and camphorsulfonic acid (CSA) followed by reduction with $\mathrm{LiAlH}_{4}$ and Swern oxidation provided aldehyde 3 in $86 \%$ yield (3 steps).

Scheme 1. Preparation of aldehyde 3

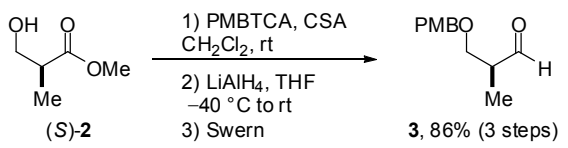

The aldol reaction between the boron enolate of acyloxazolidinone 4 and aldehyde $3(74 \%, d r>$ 95:05) followed by treatment with TBSOTf and 2,6lutidine $(72 \%)$, reduction with $\mathrm{LiBH}_{4}$ in $\mathrm{MeOH} / \mathrm{THF}$ (71\%), Swern oxidation, treatment with $\mathrm{CBr}_{4}, \mathrm{PPh}_{3}$, and 2,6-lutidine (97\%, 2 steps), and treatment with $n$-BuLi in THF provided the formation of alkyne 5 (99\%) (Scheme 2). ${ }^{2}$

The esterification of 3-hydroxy benzoic acid (6) (98\%) followed by treatment with benzyl bromide and $\mathrm{K}_{2} \mathrm{CO}_{3}(93 \%)$, provided an intermediate protected ester that was treated with $i-\mathrm{PrMgCl}$ and $\mathrm{NH}(\mathrm{Me})(\mathrm{OMe}) \cdot \mathrm{HCl}$ to provide the Weinreb amide 7 (96\%) (Scheme 3).
Scheme 2. Preparation of alkyne 5

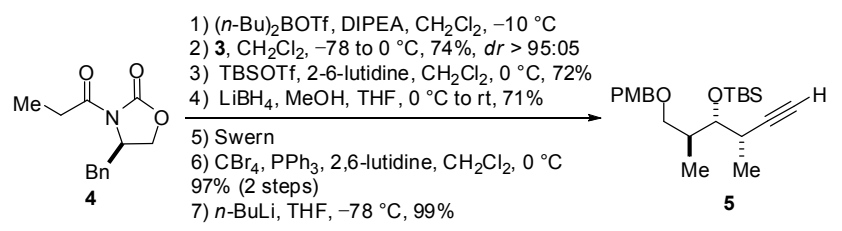

Scheme 3. Preparation of Weinreb amide 7
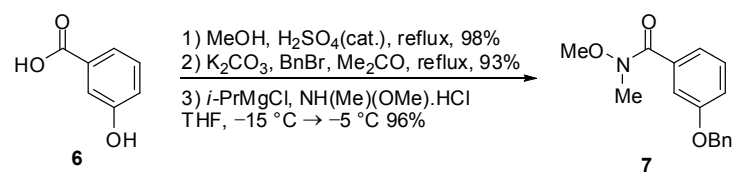

Finally, the coupling of alkyne $\mathbf{5}$ with Weinreb amide 7, mediated by $n$-BuLi, gave the ketone 8 in $50 \%$ yield (84\% brsm) (Scheme 4$)$.

Scheme 4. Preparation of ketone 8

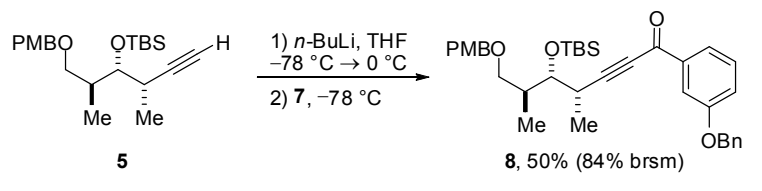

\section{CONCLUSION}

In summary, we have achieved a stereoselective synthesis of the $\mathrm{C} 1-\mathrm{C} 13$ fragment of nhatrangin $\mathrm{A}$ in 10 steps with an overall yield of $16 \%$.

\section{ACKNOWLEDGEMENTS}

We are grateful to FAPESP, CNPq and CAPES.

\section{REFERENCES}

${ }^{1}$ Chlipala, G. E.; Tri, P. H.; Hung, N. V.; Krunic, A.; Shim, S. H.; Soejarto, D. D.; Orjala, J. J. Nat. Prod. 2010, 73, 784.

${ }^{2}$ a) Dias, L. C.; Salles Jr., A. G. J. Org. Chem. 2009, 74, 5584. b) Shin, Y.; Fournier, J.-H.; Brückner, A.; Madiraju, C.; Balachandran, R.; Raccor, B. S.; Edler, M. C.; Hamel, E.; Sikorski, R. P.; Vogt, A.; Day, B. W.; Curran, D. P. Tetrahedron 2007, 63, 8537. c) Jung, W.-H.; Harrison, C.; Shin, Y.; Fournier, J.-H.; Balachandran, R.; Raccor, B. S.; Sikorski, R. P.; Vogt, A.; Curran, D. P.; Day, B. W. J. Med. Chem. 2007, 50, 2951. 